\title{
Pharmacological agents currently in clinical trials for disorders in neurogastroenterology
}

\author{
Michael Camilleri \\ Clinical Enteric Neuroscience Translational and Epidemiological Research (CENTER), Mayo Clinic, Rochester, Minnesota, USA.
}

\begin{abstract}
Esophageal, gastrointestinal, and colonic diseases resulting from disorders of the motor and sensory functions represent almost half the patients presenting to gastroenterologists. There have been significant advances in understanding the mechanisms of these disorders, through basic and translational research, and in targeting the receptors or mediators involved, through clinical trials involving biomarkers and patient responses. These advances have led to relief of patients' symptoms and improved quality of life, although there are still significant unmet needs. This article reviews the pipeline of medications in development for esophageal sensorimotor disorders, gastroparesis, chronic diarrhea, chronic constipation (including opioid-induced constipation), and visceral pain.
\end{abstract}

\section{Introduction}

Gastrointestinal motility and functional disorders result in either abnormal propulsion of content or excessive sensation of normal or abnormal functions in different regions of the gut. These conditions constitute about $40 \%$ of referrals to gastroenterologists, and they result in significant disease burden. Advances in clinical management of these disorders are based on understanding the basic mechanisms involved in sensorimotor and secretory functions, coupled with clinical investigation and trial methodology.

The most frequent gastrointestinal motility and functional disorders are esophagitis, gastroparesis, chronic diarrhea, chronic idiopathic constipation (CIC), opioid-induced constipation (OIC), and visceral pain. This review summarizes the pathophysiology, lists commonly used current medications, and focuses on pharmacological agents in development for each disorder. At present, several approved medications relieve constipation and diarrhea; the major unmet needs are in gastroparesis, OIC, and visceral pain.

\section{Mechanisms of gastrointestinal motility and sensation}

Several neurotransmitters in the gut wall and intraluminal chemicals are involved in the control of the motor, sensory, and secretory functions of the gastrointestinal tract. Peristalsis involves sensing of intraluminal stimuli such as nutrients, distension, and motion by mucosal enteroendocrine cells activating intrinsic primary afferent neurons, and release of bioactive substances such as 5-hydroxytryptamine (5-HT; also known as serotonin) and neurokinins to activate ascending contraction and descending relaxation. The main excitatory transmitters are acetylcholine and substance P; the main relaxatory substances are nitric oxide, somatostatin, and vasoactive intestinal peptide.

Afferent signals from the gut activate a three-neuron chain to transmit sensation to the central nervous system along vagal, splanchnic (visceral), and pelvic afferents. In addition, the afferents activate prevertebral, spinal, or brain reflexes that modify visceral motor and secretory functions. The neurotransmitters involved in sensation include 5-HT, substance P, calcitonin gene-

Conflict of interest: Michael Camilleri is a consultant to AstraZeneca and Tranzyme and a consultant to Albireo and Rhythm Pharmaceuticals (payment to his employer). The author's research is supported by Albireo, Rhythm Pharmaceuticals, and Theravance.

Citation for this article: J Clin Invest. 2013;123(10):4111-4120. doi:10.1172/JCI70837. related peptide, and norepinephrine. Selective modification of receptors by agonists and antagonists provide the basis for pharmacological restoration of normal motility. Figure 1 summarizes treatments for gastrointestinal motility and functional disorders.

\section{Esophageal disorders}

The common esophageal sensorimotor disorders are gastroesophageal reflux disease (GERD), esophageal spasm, and esophageal chest pain. There are several pathophysiological mechanisms that constitute targets for therapy in esophageal disease. These include excess acid contact with esophageal mucosa resulting in symptoms of heartburn or chest pain; activation of esophageal muscle contraction or increased sensitivity of the esophagus that manifest as chest pain; excessive acid reflux associated with transient lower esophageal relaxation not triggered by swallowing (TLESR; a normal function during belching) in patients with GERD; and eosinophilic esophagitis (EoE), an inflammatory process that ultimately alters the compliance and results in rings of esophageal contractions. Thus, the mainstays of current treatment remain proton pump inhibitors (PPIs), calcium channel blockers, and low-dose tricyclic antidepressants (TCAs) for reflux disease and chest pain, and orally administered or topical corticosteroids (e.g., budesonide and fluticasone) for EoE. However, new concepts are being explored with refined or novel therapeutics.

A combination of PPIs and prokinetics is being used for GERD (1). In addition to inhibition of acid secretion, this approach attempts to enhance clearance of refluxed acid, thereby reducing contact time and erosive effects of acid on the squamous epithelium in the esophageal mucosa. Different approaches to treat GERD are based on inhibition of TLESR by $\mathrm{GABA}_{\mathrm{B}}$ receptor agonists that act both centrally and peripherally (2) or selective metabotropic glutamate receptor 5 (mGluR5) antagonists (3). The prototype $\mathrm{GABA}_{B}$ agonist baclofen crosses the brain-blood barrier, causing neurologic side effects (e.g., dizziness and drowsiness). New approaches currently being tested include arbaclofen placarbil (R-isomer; prodrug of baclofen) and lesogaberan. The mGluR5 antagonist AZD2066 $(13 \mathrm{mg} / \mathrm{d})$ reduced TLESRs and reflux episodes (3).

Apart from heartburn and regurgitation, the other common esophageal symptom is noncardiac chest pain. This continues to be clinically challenging, especially when double-dose PPIs, sublingual nitrates, or TCAs do not resolve the components due to esophageal hypercontractility ("spasm”) or hypersensitivity. Other 


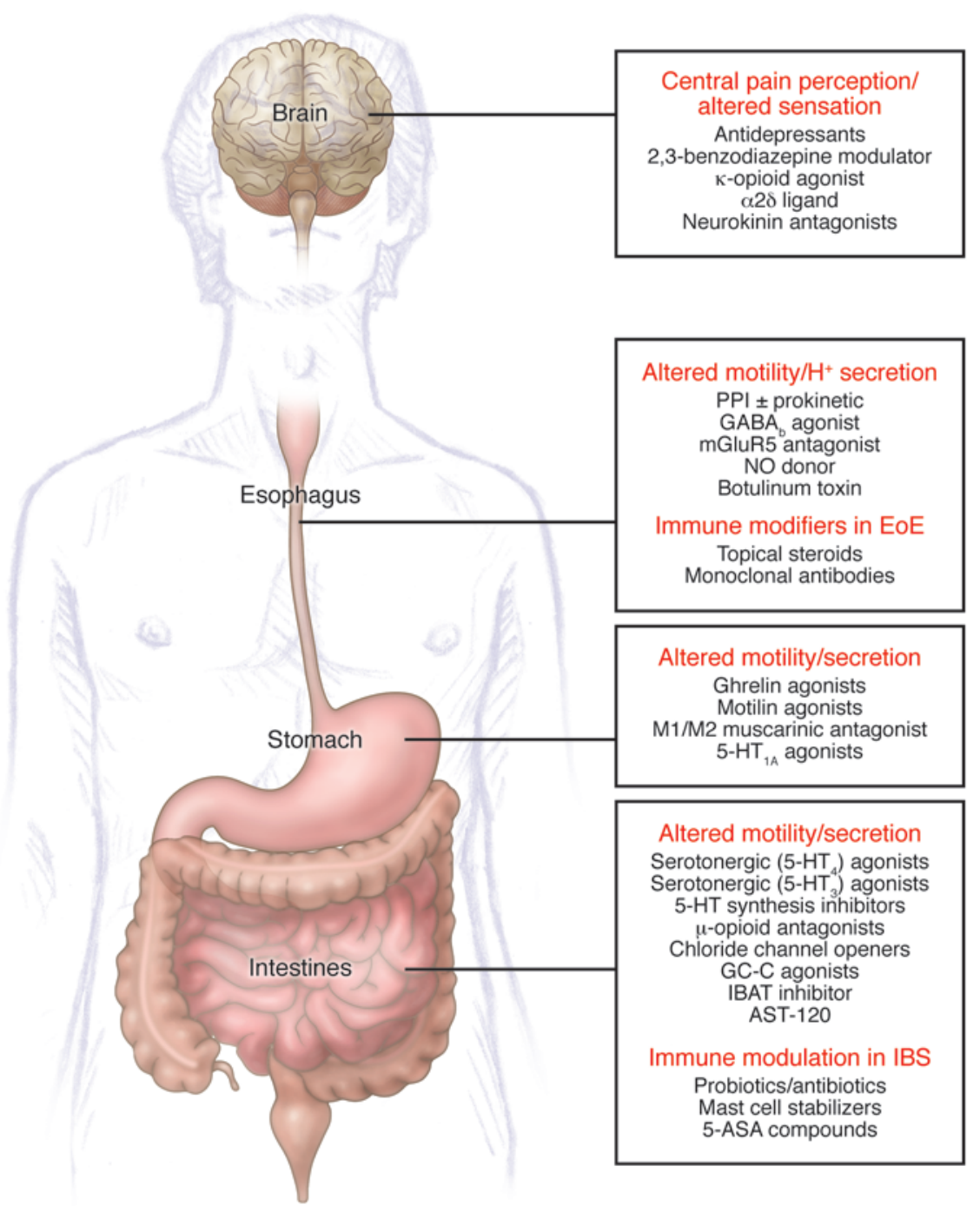

\section{Figure 1}

Classes of medications in development for treating esophageal, gastrointestinal, and colonic disorders by targeting sensation and central pain mechanisms, motility and secretion, and immune function. approaches are being tested, including NO donors (or inhibitors of NO metabolism, e.g., with sildenafil; ref. 4); both approaches increase intracellular cGMP, resulting in smooth muscle relaxation. An alternative approach in patients with esophageal spasm and pain is injection of botulinum toxin, which blocks the presynaptic release of acetylcholine from efferent nerves. In the only placebo-controlled, crossover trial of botulinum toxin for chest pain to date (5), there was reduced dysphagia, but no benefit for chest pain or reflux symptoms, in contrast to nine open-label studies (reviewed in ref. 6).

With greater understanding of the role of pain mechanisms (including acid-sensing ion channels and vanilloid receptors; ref. 7) in the esophagus, candidate pharmacological approaches include transient receptor vanilloid 1 (TRPV1) antagonists, whose pharmacology has been extensively studied (8). However, small clinical trials have not confirmed the analgesic potential of TRPV1 antagonists in human esophageal experimental pain (9).

Increased awareness of EoE in recent years has been associated with increased annual incidence, making this condition about 10 times as prevalent in a U.S. community as the classical motility disorder achalasia $(10,11)$. Food and aeroallergens are thought to play a crucial role in EoE, and first-line therapies are elimination diets and orally administered or topical corticosteroids (e.g., budes- onide and fluticasone; ref. 12). Antiinflammatory approaches to esophagitis include monoclonal antibodies directed at IL-5 and other cytokines in reflux esophagitis or eotaxin, or $\operatorname{IgE}$ in $\mathrm{EoE}$ (reviewed in ref. 13). Eotaxin is a peptide secreted by esophageal epithelial cells that functions as a strong eosinophil attractant. The high-affinity neutralizing human anti-eotaxin antibody CAT-213 inhibited eosinophil chemotactic activity in sputum from patients with moderate to severe bronchial asthma (14). The potential of monoclonal antibodies directed against eotaxin (CAT-213), IgE (omalizumab), and IL-5 (mepolizumab) in reducing chemotaxis and infiltration in EoE is the subject of ongoing research.

\section{Gastroparesis}

Gastroparesis is characterized by delayed gastric emptying in the absence of mechanical obstruction of the stomach, and symptoms include early satiety, postprandial fullness, bloating, nausea, vomiting, and abdominal or epigastric pain. Gastroparesis is usually associated with disorders in the extrinsic or intrinsic neural or pacemaker control of the stomach musculature. The most common associated conditions are postsurgical and idiopathic diabetes. Recent clinical guidelines and approved treatments for gastroparesis are reviewed elsewhere (15). The traditional molecular targets, dopamine- $\mathrm{D}_{2}$ receptor antagonists and $5-\mathrm{HT}_{4}$ receptor 
agonists, respectively suppress the vomiting center and stimulate intrinsic cholinergic neurons to activate gastric smooth muscle contractions. Short-term treatment with the motilin receptor agonist erythromycin "dumps" food and residue from the stomach, but tachyphylaxis reduces even medium-term efficacy.

The new targets in gastroparesis are receptors of ghrelin and motilin. Although there is high receptor identity, similar genomic organization, and function (stimulating gastrointestinal motility), each fails to recognize the ligand of the other. Moreover, whereas ghrelin and ghrelin receptors are widespread outside the gastrointestinal tract, motilin and its receptors are largely restricted to the gut (16).

Ghrelin receptor agonists: TZP-101, TZP-102, and RM-131. Intravenously administered ulimorelin (TZP-101), a macrocyclic peptidomimetic with potent binding affinity for the ghrelin receptor, accelerated gastric emptying of solids in 10 diabetics with moderate to severe gastroparesis symptoms (17). Small studies have shown reduced overall post-meal symptom intensity, postprandial fullness, and symptom improvement after treatment with TZP$101(80 \mu \mathrm{g} / \mathrm{kg})$ for four days in six patients with severe gastroparesis, compared with six who received placebo. This improvement was sustained in the 30 -day follow-up period $(18,19)$. Higher doses were not as effective for symptom relief as the $80-\mu \mathrm{g} / \mathrm{kg}$ dose, possibly because ghrelin receptor agonists reduce gastric accommodation, which may induce upper gastrointestinal symptoms (20).

TZP-102 is an oral ghrelin receptor agonist that was tested in a 28-day placebo-controlled, dose-response trial in 92 patients with diabetic gastroparesis and moderate to severe symptoms. The 20-mg TZP-102 dose was superior to placebo for nausea, early satiety, postprandial fullness, bloating, upper abdominal pain, and patient-reported overall treatment effect (21). In patients with baseline gastric emptying $t_{1 / 2}$ exceeding 168 minutes (on ${ }^{13} \mathrm{C}$-octanoate breath test), TZP-102 did not accelerate gastric emptying, but it reduced a composite symptom score of nausea, inability to finish meals, upper abdominal pain, and bloating (22). However, in a preliminary report of a randomized, placebo-controlled, 12-week trial of 10 and $20 \mathrm{mg}$ oral TZP-102 in 201 patients with diabetic gastroparesis, there was no significant symptomatic benefit of either dose over placebo (23).

RM-131, a pentapeptide synthetic ghrelin receptor agonist, has a longer plasma $t_{1 / 2}$ and more than 100 -fold the potency in reversing ileus in animals compared with native ghrelin. The effects of RM-131 (100 $\mu$ g, s.c.) and placebo were tested in two randomized, crossover studies in patients with type 1 or 2 diabetes, upper gastrointestinal symptoms, and prior documented gastric emptying delay. In both studies, Shin et al. demonstrated that RM-131 accelerated gastric emptying and reduced gastrointestinal symptoms $(24,25)$. Results from phase IIB studies are required to appraise symptom benefit.

Motilin receptor agonist: GSK962040. GSK962040 is a nonmotilide motilin receptor agonist with low molecular mass that increases gastrointestinal motility in dogs (26). It selectively activates the motilin receptor in humans; activates predominantly antrum rather than fundus, small intestine, or colon in human tissue in vitro (27); and has been evaluated to determine safety and tolerability in humans (28). It is currently being investigated in phase 2 clinical trials (ClinicalTrials.gov trial ID NCT01262898).

\section{Chronic diarrhea}

In the absence of mucosal diseases, such as celiac and inflammatory bowel diseases, chronic diarrhea generally results from increased intestinal or colonic motility or secretion, increased colorectal sensitivity, or altered intestinal content and barrier function. The roles of intraluminal milieu, including microbial flora, organic (bile and short-chain fatty acids), and intestinal permeability are under investigation. Bile acid malabsorption (BAM) accounts for approximately $25 \%$ of patients with chronic diarrhea (29). This can be positively diagnosed by ${ }^{75} \mathrm{SeHCAT}$ retention (30), measurement in serum of $7 \alpha$-hydroxy-4-cholesten-3-1 (31), or quantitative fecal bile acid measurement $(32,33)$; regrettably, such tests are not available in the United States, and response to a bile acid sequestrant is most commonly used to tentatively diagnose BAM.

Current treatments of chronic diarrhea are opioids, such as loperamide (the first-line drug) and diphenoxylate, which may be combined with atropine in some formulations and may induce adverse effects, such as bladder dysfunction, glaucoma, and tachycardia. Bile acid binders - classically, cholestyramine (4 g, 3 times per day) and off-label colesevelam (625 mg, 1-3 tablets 2 times per day) - are indicated for BAM.

Alosetron, a $5-\mathrm{HT}_{3}$ receptor antagonist, is approved for severe, diarrhea-predominant irritable bowel syndrome (IBS-D) that is not responding to other therapy. Alosetron was initially withdrawn because of reported association with ischemic colitis. Drugs approved for other indications are commonly used in IBS-D; these include opioids, other $5-\mathrm{HT}_{3}$ receptor antagonists (such as ondansetron), and psychoactive agents (with anticholinergic effects). Nonabsorbable antibiotics appear not to be effective for chronic diarrhea. Thus, rifaximin, a nonabsorbable antibiotic, was associated with adequate relief that was even documented for 10 weeks after cessation of treatment (34); however, stool consistency and number and urgency of bowel movements were not improved. Similarly, a meta-analysis that included five clinical trials demonstrated global IBS symptom and bloating improvement, but no significant effect on bowel function (35). Future treatments for chronic diarrhea are summarized in Table 1, and salient features are highlighted here.

5-HT synthesis inbibition. About $90 \%$ of the body's 5-HT is located in the enterochromaffin cells in the gastrointestinal tract mucosa. Mucosal 5-HT receptors are involved in secretion, motility, and nociception (36). LX-1031 is an oral tryptophan hydroxylase (TPH) inhibitor that reduces synthesis of 5-HT peripherally (37) without crossing the blood-brain barrier, thus avoiding risk of depression. In a randomized, placebo-controlled, 4-week, phase II trial, dose-dependent reductions in 5-HT correlated with adequate relief and improved stool consistency in the 1,000-mg dose group (38). No phase III trials have been reported to date.

New 5-HT receptor antagonist: ramosetron. A selective 5- $\mathrm{HT}_{3}$ receptor antagonist, ramosetron, slows colonic transit and reduces pain sensation in animal models subjected to stress $(39,40)$. Ramosetron $(5$ and $10 \mu \mathrm{g})$ was tested in two studies of approximately 1,000 patients with IBS-D and was superior to placebo in global relief of symptoms, with similar efficacy in men and women. Constipation and hard stool occurred in approximately $5 \%$ of patients (41, 42 ). Ramosetron ( $5 \mu \mathrm{g}$, once per day) is as effective as the antispasmodic mebeverine ( $135 \mathrm{mg}, 3$ times per day) in male patients with IBS-D (43). It is still unclear whether ramosetron causes ischemic colitis, which had been observed with alosetron.

Muscarinic type 3 receptor antagonists. Darifenacin retarded human small bowel and colonic transit (44), otilonium reduced rectal sensations (45), and hyoscine reduced enterocyte secretion (46). Therefore, this class of agents can counteract three mechanisms 
Table 1

Examples of new medications for chronic diarrhea

\section{Examples of new medications for chronic diarthea}

\section{Drug}

\section{Rationale and}

putative action

$\mathrm{TPH}_{1}$ blockers

LX-1031

Inhibits synthesis of

5- $\mathrm{HT}$ by blocking $\mathrm{TPH}_{1}$

\section{5- $\mathrm{HT}_{3}$ antagonists}

Ramosetron

Inhibits secretion, motility, nociception

\section{Muscarinic type 3 receptor antagonists}

Otilonium

Inhibits secretion, motility, nociception

Darifenacin

Inhibits secretion, motility, nociception

Solifenacin Inhibits secretion, motility, nociception

Oral carbon adsorbents

AST-120

Adsorbs luminal

factors causing colon dysfunction

\section{Mast cell stabilizers}

DSCG

Ketotifen

Mesalamine, mesalazine

Reduces mucosal

inflammation

\section{2,3-benzodiazepine modulators}

Dextofisopam

Potential to reduce colonic motility and visceral sensitivity

\section{К-opioid agonists}

Asimadoline

$\kappa$-opioid receptors

in visceral perception

\section{Amino acids}

Glutamine immune activation, immune activation, visceral sensitivity

Pharmacodynamics
in humans

Clinical efficacy

Inhibited urine 5-HIAA

excretion; no studies of PD efficacy

Phase IIB trial in non-IBS-C $(1,000 \mathrm{mg})$ :

improved adequate relief, stool consistency

ND

Phase IIB studies in IBS-D (5 and $10 \mu \mathrm{g})$ : benefit on global relief and bowel function

Increased rectosigmoid distention sensory thresholds

Retarded small bowel and colonic transit

ND

ND visceral sensitivity

\section{Reduced jejunal biopsy mast cell mediators in IBS patients \\ Increased rectal sensation threshold in those with baseline visceral hypersensitivity}

Reduced proteases, cytokines in colonic biopsies in IBS

None

Reduced sensation of colon distensions in healthy; increased sensory thresholds in IBS

Potential to correct for lower glutamine synthase in IBS
Phase IV studies: greater relief of pain vs. placebo, equivalence to mebeverine

ND

Open-label phase IIB trial (2.5-10 mg): equivalent efficacy to $5 \mu \mathrm{g}$ ramosetron

Phase IIB study in non-IBS-C: reduced pain and bloating, improved stool consistency

Phase IV study: enhanced benefit from food restriction diet in IBS-D patients with food "allergies"

Phase IIA study: relief of symptoms and pain in subset with baseline visceral hypersensitivity

Phase IIA small studies: 2 of 4 showed relief of pain or diarrhea

Phase IIB study in IBS: increased number of months of adequate overall relief of IBS symptoms

Phase IIB dose-ranging study: at least average benefit for moderate pain in IBS-D and IBS-A

Phase IIB study: improved abdominal pain, bloating, and diarrhea
Safety issues, approval, other

Under investigation

Under investigation; ischemic colitis with same drug class (alosetron)

EMA approved Under investigation

Under investigation

Under investigation

Off-label use

Somnolence; off-label use

Off-label use

Under investigation

Under investigation

Off-label use

HIAA, hydroxyindoleacetic acid; PD, pharmacodynamic. Adapted from ref. 71 and ref. 120.

that contribute to chronic diarrhea. Clinical trials show greatest effect of otilonium on abdominal sensation rather than bowel dysfunction in patients with IBS $(47,48)$. A small trial using crossover design showed similar efficacy of solifenacin and ramosetron (49).

Carbon adsorbent: AST-120. AST-120 consists of porous, spherical carbon particles of $0.2-0.4 \mathrm{~mm}$ diameter and large surface area $\left(1,600 \mathrm{~m}^{2} / \mathrm{g}\right)$; it adsorbs small-molecular weight and bacterial toxins, inflammatory mediators, digestive enzymes, and bile acid products (50). In a phase II, 8-week treatment trial, AST-120 transiently reduced pain and bloating in 115 patients with IBS-D or alternating IBS (IBS-A); however, stool consistency was not significantly improved (51).

Mast cell stabilizers. Disodium cromoglycate (DSCG) inhibits mast cell release of mediators such as histamine, leukotrienes, and a slow-reacting substance of anaphylaxis. A small study in IBS-D tested no treatment $(n=7)$ or oral DSCG $(200 \mathrm{mg}, 3$ times per 
day; $n=11)$. Six months later, DSCG was associated with reduced release of tryptase from jejunal biopsies, reduced expression of TLR2 and TLR4, and improved bowel function $(52,53)$. In an earlier study of 66 IBS-D patients with food intolerance assessed by skin prick test, DSCG (250 mg, 4 times per day) plus exclusion diet was associated with prolonged symptomatic benefit compared with exclusion diet alone (54).

Ketotifen, a mast cell stabilizer with antihistamine effects, was compared with placebo in 60 IBS patients (unselected for subgroup; ref. 55); it reduced discomfort induced by rectal balloon distension in 30 IBS patients with visceral hypersensitivity, but not in 30 normosensitive IBS patients. Compared with placebo, ketotifen had beneficial effects on pain, bloating, flatulence, diarrhea, quality of life, sleep, and sexual function. Side effects included sedation and drowsiness. In the future, nonsedating mast cell stabilizers will need to be tested.

5-aminosalicylic acid agents. The mechanism of 5-aminosalicylic acid (5-ASA) benefit in IBS may reflect reduced total colonic mucosal immunocytes and mast cells and mucosal release of IL-1 $\beta$, histamine, and tryptase (56). Two of four small clinical trials suggest it may be beneficial in IBS patients, including some benefit on bowel function. In a 20-patient study, general well-being was improved, but the colonic symptoms did not change (56). In a trial involving 12 IBS-D patients, mesalazine ( $1.5 \mathrm{~g}, 2$ times per day) was associated with symptomatic response of global relief, decreased number of days with discomfort, and increased bowel movement satisfaction in 8 patients (57). Mesalazine induced relief of pain and diarrhea in patients with these predominant symptoms in a third trial (58), but efficacy was not replicated in a recent small trial (59).

Benzodiazepine receptor modulator dextofisopam. Dextofisopam binds to the 2,3-benzodiazepine receptors in subcortical ganglia, substantia nigra, and hypothalamus and does not induce sedation. These receptors are not located in the gastrointestinal tract. Dextofisopam reduced gastrointestinal motor dysfunction and visceral sensitivity in response to stress in an animal model of IBS (60). In a 4-week, placebo-controlled trial, dextofisopam (200 mg, 2 times per day) improved consistency and frequency of bowel movements in patients with IBS-D or IBS-A (61). Further studies of action, safety, and efficacy in humans are required.

Peripheral $\kappa$-opioid receptor agonist: asimadoline. The $\kappa-, \mu$-, and $\delta$-opioid receptors are distributed widely in the central and peripheral nervous systems. Peripheral $\kappa$-opioid receptor agonists do not induce central side effects, but they reduce visceral sensation. The $\kappa$-opioid receptor agonist asimadoline, which does not cross the blood-brain barrier, reduced pain sensation (62) with no significant effects on gastrointestinal transit or colonic motility (63); however, asimadoline reduced urgency and stool frequency in IBS-D patients who had at least moderate pain at baseline (64).

Glutamine. Patients with IBS-D have increased permeability and symptomatic IBS (65) and decreased intestinal glutamine synthetase levels. In a preliminary report of a trial of glutamine (10 g, 3 times per day) in 61 IBS-D patients with high intestinal permeability and reduced claudin-1 expression in intestinal biopsies (66), the glutamine treatment arm was associated with significantly improved abdominal pain, bloating, and diarrhea as well as restored intestinal permeability compared with placebo.

\section{CIC and OIC}

$\mathrm{CIC}$ is associated with reduced colonic motility; however, in one tertiary referral study, almost $30 \%$ of patients with chronic consti- pation had evidence of rectal evacuation disorders (67). Patients with evacuation disorders are less likely to respond to colonic prokinetic agents, as demonstrated in a comparison of prucalopride and PEG3350 in patients with chronic constipation, many of whom endorsed symptoms suggestive of rectal evacuation disorders (68). Chronic constipation with hard stools reflects absorption of water, possibly from deficiency of natural colonic secretagogues (e.g. endogenous, secretory bile acids, particularly chenodeoxycholic acid; refs. 33, 69).

There are many approved treatments for CIC, including osmotic laxatives (e.g., PEG3350 and magnesium salts), surface active agents (e.g., docusate), stimulants (e.g., bisacodyl and senna alkaloids), and the recently approved secretagogues lubiprostone (rINN; trade name Amitiza) and linaclotide, which activate chloride secretion through chloride- 2 channels and cystic fibrosis transmembrane regulator (CFTR).

\section{New approaches to treat $\mathrm{CIC}$}

There are three general categories of medications in development for the treatment of CIC: colonic prokinetics $\left(5-\mathrm{HT}_{4}\right.$ receptor agonists), new secretagogues, and bile acid modulators. Medications are being specifically developed for OIC, including peripherally restricted $\mu$-opioid receptor antagonists (PAMORAs). These medications are summarized in Table 2.

$5-\mathrm{HT}_{4}$ receptor agonists. Whereas older-generation $5-\mathrm{HT}_{4}$ receptor agonists (e.g., cisapride) had relatively poor receptor selectivity and affected other receptors or ion channels in the heart (e.g., the delayed rectifier $\mathrm{K}^{+}[\mathrm{IKr}]$ channel) with risk of cardiac arrhythmias unrelated to the $5-\mathrm{HT}_{4}$ receptor, the new-generation $5-\mathrm{HT}_{4}$ receptor agonists have more than 100-fold greater selectivity for $5-\mathrm{HT}_{4}$ receptors than for the IKr channel, great specificity at intestinal 5- $\mathrm{HT}_{4}$ receptors, and low intrinsic activity in cardiac muscle (70).

Agonists at $5-\mathrm{HT}_{4}$ receptors induce fast excitatory postsynaptic potentials in intrinsic neurons, release neurotransmitters such as acetylcholine, and induce mucosal secretion by activating submucosal neurons. Three $5-\mathrm{HT}_{4}$ receptor agonists in development are prucalopride, velusetrag, and naronapride (Table 2 and ref. 71 ). There is considerable evidence supporting prucalopride's pharmacodynamic effects, safety, and efficacy in chronic constipation (72); it is approved in most countries, but not in the United States. Velusetrag and naronapride are also in development in phase IIB studies. Both have been efficacious in pharmacodynamic studies (71), and velusetrag is efficacious in patients with chronic constipation (73).

New chloride secretagogues. Plecanatide activates guanyl cyclase $\mathrm{C}$ (GC-C) receptors in intestinal epithelium, stimulating chloride and bicarbonate secretion through the opening of apical CFTR chloride channels (74) and inhibition of sodium absorption through blockade of an apical $\mathrm{Na}^{+} / \mathrm{H}^{+}$exchanger. In a 14-day treatment trial in 80 patients with CIC, plecanatide improved stool frequency and consistency, straining, and abdominal discomfort (75). A preliminary report documents the efficacy of plecanatide $(0.3,1$, and $3 \mathrm{mg})$ in 951 CIC patients treated for 12 weeks (76).

Bile acid modulation. Delivery of bile acids into the colon results in secretory diarrhea, increasing permeability, activating adenylate cyclase, and increasing colonic motility. A novel approach to bile acid delivery to the colon involves selective inhibition of the ileal bile acid transporter (IBAT) with elobixibat (A3309). This drug accelerated colonic transit (77) and significantly increased stool frequency and improved constipation-related symptoms over 8 weeks of treatment in CIC patients (78). Long-term exposure to 
Table 2

Examples of new drugs for CIC and OIC

\section{Clinical trial optimal efficacy and safety}

$\begin{array}{ll}\text { Drug class Drug name } & \begin{array}{l}\text { Pharmacodynamic efficacy } \\ \text { in humans }\end{array}\end{array}$

\section{CIC}

Benzofuran

$5-\mathrm{HT}_{4}$ agonist

Prucalopride

Accelerated colonic transit in health and chronic constipation

$\begin{array}{lll}\begin{array}{c}\text { Quinolone } \\ \text { 5- } \mathrm{HT}_{4} \text { agonist }\end{array} & \text { Velusetrag } & \begin{array}{l}\text { Accelerated colonic transit in health } \\ \text { in dose-related fashion }\end{array} \\ \begin{array}{c}\text { Benzamide } \\ \text { 5- } \mathrm{HT}_{4} \text { agonist }\end{array} & \text { Naronapride } & \text { Accelerated colonic transit in health } \\ \text { IBAT inhibitor } & \text { Elobixibat } & \begin{array}{l}\text { Accelerated colonic transit in } \\ \text { female chronic constipation }\end{array} \\ \begin{array}{c}\text { GC-C receptor } \\ \text { activation }\end{array} & \text { Plecanatide } & \text { ND }\end{array}$

OIC

Nonselective opioid antagonist $\mu$-opioid antagonist

\author{
$\mu$-opioid antagonist \\ as core $(4 \%$ \\ naltrexone/ \\ morphine ratio)
}

\begin{abstract}
PAMORA
\end{abstract}
PAMORA; PEGylated naloxol

PAMORA
$\mu$-opioid agonist
plus norepinephrine
reuptake inhibitor

Oral naloxone

Methylnaltrexone

Reversed opiate-induced delay in orocecal and colonic transit

Reversed effects of opiate in health an of chronic methadone treatment on orocecal transit; no effect on colonic transit delayed by codeine ( $30 \mathrm{mg}, 4$ times per day) in opiate-naive healthy

Naltrexone ER ND

$8 \mathrm{mg}$ accelerated colonic transit, reverse delayed colonic transit by codeine (30 mg, 4 times per day) in opiate-naive healthy

NKTR-118

Normalized morphine-induced delay in orocecal transit

$$
\text { TD-1211 }
$$

Tapentadol

ND

Delayed gastric emptying; no retardation of colonic transit
Phase II and III trials completed; open-label EMA experience of $\sim 1,000$ cumulative patient-years; no clinical cardiac adverse events in clinical trials of $>4,000$ humans

Phase IIB efficacy; no effect on QT in health or in 400 patients with constipation Phase IB efficacy

Phase IIA and IIB efficacy

Phase IIA and IIB efficacy in chronic constipation

Naloxone PR formulation prevents OIC in patients receiving $\mathrm{PR}$ oxycodone

Methylnaltrexone $(0.15 \mathrm{mg} / \mathrm{kg}$ s.c., alternate days) effective in inducing laxation in patients with advanced illness

Open-label 12-month safety of combination

ER pellets of morphine (median $59 \mathrm{mg} / \mathrm{d}$ )

with a sequestered naltrexone core (1 or 2

times per day); OIC, $31.8 \%$, nausea, $25.2 \%$; opiate withdrawal, $<5 \%$

Alvimopan ( $0.5 \mathrm{mg}, 2$ times per day)

efficacious in treating $\mathrm{OIC}$; rare

instances of ischemic heart disease

NKTR-118 (25 and $50 \mathrm{mg}$ ) increased number of SBMs during the first week and 4 overall weeks of treatment of OIC patients TD-1211 (5 and $10 \mathrm{mg} / \mathrm{d}$ ) increased average SBM/wk over 2 weeks in OIC patients

Tapentadol ER (100-250 mg 2 times per day) equally effective for moderate to severe chronic osteoarthritis-related knee pain or chronic low back pain compared with oxycodone HCI CR (20-50 mg, 2 times per day) with fewer bowel dysfunction symptoms

$\begin{array}{lll}\text { Bicyclic fatty acid } & \text { Lubiprostone } & \text { ND } \\ 5-\mathrm{HT}_{4} \text { agonist } & \text { Prucalopride } & \text { ND }\end{array}$

Phase III clinical trials of lubiprostone (24 $\mu \mathrm{g}, 2$ times per day); 2 of 3 positive

1 phase IIB trial of prucalopride (2 or $4 \mathrm{mg} / \mathrm{d}$ ) shows efficacy
Under investigation

$-$

Off-label

FDA,

Canada

\section{Approval status}

(1)

Under investigation

-

-

EMA

Off-label

Under investigation

Under investigation

Off-label
FDA

Off-label

CR, controlled release; ER, extended release; ND, not done. Adapted from ref. 13 and ref. 71.

high colonic bile acids after partial ileal bypass for hyperlipidemia was not associated with increased prevalence of colorectal cancer at 25-year follow-up (79).

\section{New approaches to treat OIC}

The $\delta$-, $\kappa$-, and $\mu$-opioid receptors (all GPCRs) affect human gastrointestinal function, reducing neuronal excitability and neurotrans- mitter (acetylcholine) release (80) in nonsphincteric muscle, increasing tone in gastrointestinal sphincters such as the pylorus and ileocecal region, and inhibiting transit (81). About $40 \%$ of patients receiving long-term opioid treatment for noncancer chronic pain (most frequently musculoskeletal) experience OIC. The presence of constipation may influence patients to reduce analgesic dose, thereby not achieving effective pain relief. Moreover, less than $50 \%$ of 
patients with OIC report achieving satisfaction with laxatives more than $50 \%$ of the time (82). Opiates cause constipation by inhibiting colonic transit and reducing intestinal and colonic secretion. There are three approaches to resolving this form of chronic constipation: avoidance, reversal with $\mu$-opioid receptor antagonists, and overcoming the inhibitory effects of opiates by inducing intestinal and colonic secretion or motility. Approved medications include tapentadol (avoidance of OIC) as well as naloxone and methylnaltrexone ( $\mu$-opioid receptor antagonists). These and experimental therapies for OIC are summarized in Table 2.

Tapentadol $\mathrm{HCl}$ is a $\mu$-opioid agonist and norepinephrine reuptake inhibitor that has approximately equivalent pain relief efficacy, but a more favorable gastrointestinal side-effect profile than the classic $\mu$-opioid receptor agonist, oxycodone, for chronic pain related to arthritis, back pain, or postoperative analgesia (83-85).

Although $\mu$-opioid receptor antagonists can reverse OIC, the widespread tissue distribution (e.g., with naloxone) can inhibit central actions of opioids, causing withdrawal symptoms or blocking the analgesia (86).

Modifications of naloxone are efficacious in OIC. A prolongedrelease (PR) naloxone preparation in combination with PR oxycodone was effective for moderate to severe chronic pain (87) and improved bowel function compared with oral PR oxycodone alone (88), even up to 52 weeks in patients with noncancer chronic pain (89).

Several PAMORAs with modest central nervous system penetration are in development, including methylnaltrexone, alvimopan (Entereg), naloxegol (NKTR-118), and TD-1211. The pharmacodynamic effects of these agents are reviewed elsewhere (90). Methylnaltrexone is FDA approved in the United States for the treatment of OIC in patients receiving palliative care when response to laxative therapy has not been sufficient (91); however, it is not yet approved for adults with chronic, noncancer pain.

Alvimopan is an orally administered PAMORA that does not cross the blood-brain barrier at clinically relevant doses. In several clinical trials in patients with OIC and noncancer pain, alvimopan restored bowel movements without compromising analgesia (91-93), although superiority over placebo was not demonstrated in one phase III trial (94).

Naloxegol is an oral PEGylated conjugate of naloxone with rapid absorption, opioid receptor antagonist properties peripherally, and reduced central nervous system penetration. Three randomized, controlled trials in OIC patients showed that naloxegol $(12.5$ or $25 \mathrm{mg} / \mathrm{d})$ significantly increased numbers of spontaneous bowel movements (SBMs) and OIC responders over 12 weeks (based on a rigorous, composite, FDA-sanctioned endpoint), with no evidence of opioid withdrawal or reversal of analgesia $(95,96)$.

TD-1211 is a PAMORA with high affinity for human $\mu$ - and $\delta$-opioid receptors that reverses opiate-induced inhibition of colonic motility without reversing the central or analgesic effects (97). In a phase IIa study in 70 patients with OIC, TD-1211 (5 and 10 mg, once per day) significantly increased the average number of SBMs per week and shortened median time to first SBM (98). In a 5-week phase IIb study in 217 chronic noncancer pain OIC patients, TD-1211 (10 and $15 \mathrm{mg}$ ) significantly increased complete SBMs and SBMs per week (99).

Two meta-analyses of $\mu$-opioid receptor antagonists involving 22 articles (100) or 20 studies (101) generally showed proof of concept, but insufficient clinical efficacy. These analyses did not include the newer medications, such as TD-1211 or naloxegol.

The third approach to treating OIC does not target opiate receptors, but increases secretion or motility to relieve the OIC. Prucalo- pride ( 2 or $4 \mathrm{mg}$ for 4 weeks) was efficacious in a phase II study of 196 patients with OIC compared with placebo (102).

Lubiprostone is a prostaglandin E1-derived bicyclic fatty acid that specifically activates CIC-2 chloride channels on the apical aspect of gastrointestinal epithelial cells, increasing chloride release. Its effects in vitro and in vivo in models of OIC are reviewed elsewhere (90). Lubiprostone ( $24 \mu \mathrm{g}, 2$ times per day) was recently approved by the FDA for treatment of OIC related to noncancer pain, based on three phase IIB or III trials $(103,104)$. In vitro studies suggest that lubiprostone may not be effective in reversing OIC caused by methadone treatment (105).

\section{Drugs for visceral pain associated with gastrointestinal motility disorders}

The neurotransmitters involved in sensation include 5-HT, substance $\mathrm{P}$, calcitonin gene-related peptide, and norepinephrine. There are no drugs approved for visceral pain in motility and functional disorders; the most frequently used off-label medications are antidepressants in both IBS and functional dyspepsia. A Cochrane meta-analysis showed a beneficial effect over placebo for improvement of abdominal pain with antispasmodics, cimetropium, dicyclomine, peppermint oil, pinaverium, and trimebutine, of which only peppermint oil is available in the USA. There was also a beneficial improvement of abdominal pain over placebo for TCAs, but not for selective 5-HT reuptake inhibitors (106). TCAs are also being used for other symptomatic disorders. A preliminary report of the TCA nortriptyline in 130 patients with idiopathic gastroparesis showed no significant symptomatic relief over placebo (107). The field of drug development for visceral pain should be enhanced by the demonstration that different endpoints recommended by two regulatory agencies, the FDA and the European Medicines Agency (EMA), were associated with similar response rates when applied in a large database of constipation-predominant IBS (IBS-C) patients participating in two phase III trials (108).

Two drugs in development for relief of visceral pain in IBS-D and IBS-A are asimadoline and dextofisopam (discussed above). Asimadoline failed to improve symptoms in a small pilot study of patients with functional dyspepsia (109).

Glucagon-like peptide-1 (GLP-1) is an incretin that suppresses gastric and small intestinal motility. The GLP-1 analog ROSE-010 (s.q. injection) was effective in twice as many patients as placebo when evaluated for on-demand treatment of IBS pain episodes in a crossover, double-blind, randomized design (110). As expected, ROSE-010 slowed gastric emptying, but it did not retard colonic transit or alter gastric accommodation (111).

A preliminary report assessed the efficacy of a histamine H1-receptor antagonist, ebastin, in the treatment of visceral pain associated with IBS in a 12-week trial with 28 patients randomized to ebastin and 27 to placebo (112). Visual analog scale (VAS) pain scores of symptoms evoked by rectal distentions (a pharmacodynamics endpoint) were not significantly influenced by treatment group; however, treatment over 12 weeks was associated with considerable relief of symptoms in $46 \%$ of the ebastin group and $12 \%$ of placebo group. There were also lower average abdominal pain scores with ebastin.

Ibodutant is a selective and potent antagonist of $\mathrm{NK}_{2}$ receptors, which reduced intestinal hypermotility and hyperalgesia in disease models. Oral ibodutant (1, 3, and $10 \mathrm{mg}$, once per day) was compared with placebo for 8 weeks in 559 patients with IBS-D (Rome III criteria), which showed a significant effect of the $10-\mathrm{mg} / \mathrm{d}$ dose in females in a prespecified analysis (113). These data contrast with 
other studies of other neurokinin receptor antagonists, such as talnetant, and suggest that $\mathrm{NK}_{2}$ receptors may be optimal targets for visceral pain and diarrhea (113).

Two drug classes are in development for the relief of symptoms arising from functional dyspepsia, which is associated with motor dysfunctions such as impaired gastric emptying and reduced gastric accommodation (114). An approved $5-\mathrm{HT}_{1 \mathrm{~A}}$ receptor agonist, buspirone ( $10 \mathrm{mg}$, 3 times per day), enhanced gastric accommodation and provided symptom improvement in 17 patients with functional dyspepsia in a 4-week, placebo-controlled, crossover study (115). Similarly, an experimental $5-\mathrm{HT}_{1 \mathrm{~A}}$ receptor agonist, tandospirone ( $10 \mathrm{mg}$, 3 times per day), reduced abdominal symptom scores (including pain and discomfort) and anxiety in a 4-week, placebocontrolled study of 144 patients with functional dyspepsia (116).

Acotiamide enhances acetylcholine release via antagonism of M1 and M2 muscarinic receptors and functions as a cholinesterase inhibitor (117). In a multicenter, placebo-controlled, randomized trial involving 892 Japanese patients with functional dyspepsia (postprandial distress syndrome by Rome III criteria), oral acotiamide (100 mg, 3 times per day) was more efficacious than placebo for overall efficacy and for elimination of early satiation, upper abdominal bloating, and postprandial fullness (118). The mechanisms of action of acotiamide are enhanced gastric accommodation and gastric emptying (119).

1. Cho YK, et al. Effect of mosapride combined with esomeprazole improves esophageal peristaltic function in patients with gastroesophageal reflux disease: a study using high resolution manometry. Dig Dis Sci. 2013;58(4):1035-1041.

2. Kuo P, Holloway RH. Beyond acid suppression: new pharmacologic approaches for treatment of GERD. Curr Gastroenterol Rep. 2010;12(3):175-180.

3 . Rohof WO, et al. The effects of a novel metabotropic glutamate receptor 5 antagonist (AZD2066) on transient lower oesophageal sphincter relaxations and reflux episodes in healthy volunteers. Aliment Pharmacol Ther. 2012;35(10):1231-1242.

4. Fox M, Sweis R, Wong T, Anggiansah A. Sildenafil relieves symptoms and normalizes motility in patients with oesophageal spasm: a report of two cases. Neurogastroenterol Motil. 2007;19(10):798-803.

5. Vanuytsel T, et al. Botulinum toxin reduces dysphagia in patients with non-achalasia primary esophageal motility disorders. Clin Gastroenterol Hepatol. 2013;pii:S1542-3565(13)00461-8.

6. Hershcovici T, Achem SR, Jha LK, Fass R. Systematic review: the treatment of noncardiac chest pain. Aliment Pharmacol Ther. 2012;35(1):5-14.

7. Bredenoord AJ. Mechanisms of reflux perception in gastroesophageal reflux disease: a review. $A m J$ Gastroenterol. 2012;107(1):8-15.

8. Peles S, et al. Differential effects of transient receptor vanilloid one (TRPV1) antagonists in acid-induced excitation of esophageal vagal afferent fibers of rats. Neuroscience. 2009;161(2):515-525.

9. Krarup AL, et al. Randomized clinical trial: inhibition of the TRPV1 system in patients with nonerosive gastroesophageal reflux disease and a partial response to PPI treatment is not associated with analgesia to esophageal experimental pain. Scand J Gastroenterol. 2013;48(3):274-284.

10. Prasad GA, et al. Epidemiology of eosinophilic esophagitis over three decades in Olmsted County, Minnesota. Clin Gastroenterol Hepatol. 2009;7(10):1055-1061.

11. Podas T, Eaden J, Mayberry M, Mayberry J. Achalasia: a critical review of epidemiological studies. Am J Gastroenterol. 1998;93(12):2345-2347.

12. Dellon ES, et al. ACG clinical guideline: Evidenced based approach to the diagnosis and management of esophageal eosinophilia and eosinophilic esoph- agitis (EoE). Am J Gastroenterol. 2013;108(5):679-692.

13. Katzka DA, Loftus EV Jr, Camilleri M. Evolving molecular targets in the treatment of nonmalignant gastrointestinal diseases. Clin Pharmacol Ther. 2012;92(3):306-320.

14. Dent G, et al. Contribution of eotaxin-1 to eosinophil chemotactic activity of moderate and severe asthmatic sputum. Am J Respir Crit Care Med. 2004; 169(10):1110-1117.

15. Camilleri M, Parkman HP, Shafi MA, Abell TL, Gerson L, American College of Gastroenterology. Clinical guideline: management of gastroparesis. Am J Gastroenterol. 2013;108(1):18-37.

16. Sanger GJ, Wang Y, Hobson A, Broad J. Motilin: Toward a new understanding of the gastrointestinal neuropharmacology and therapeutic use of motilin receptor agonists [published online ahead of print November 28, 2012]. doi:10.1111/bph.12075.

17. Ejskjaer N, et al. Ghrelin receptor agonist (TZP101) accelerates gastric emptying in adults with diabetes and symptomatic gastroparesis. Aliment Pharmacol Ther. 2009;29(11):1179-1187.

18. Ejskjaer N, et al. Safety and efficacy of ghrelin agonist TZP-101 in relieving symptoms in patients with diabetic gastroparesis: a randomized, placebocontrolled study. Neurogastroenterol Motil. 2010; 22(10):1069-e281.

19. Wo JM, et al. Randomised clinical trial: ghrelin agonist TZP-101 relieves gastroparesis associated with severe nausea and vomiting--randomised clinical study subset data. Aliment Pharmacol Ther. 2011;33(6):679-688.

20. Ang D, et al. Influence of ghrelin on the gastric accommodation reflex and on meal-induced satiety in man. Neurogastroenterol Motil. 2009;21(5):528-533.

21. McCallum R, et al. TZP-102, ghrelin agonist phase 2 data: the improvement in symptoms of gastroparesis (nausea, early satiety, bloating and abdominal pain) significantly correlated with patient rating of overall treatment effect. Gastroenterology. 2011;140(5):S807.

22. Ejskjaer $\mathrm{N}$, et al. A phase $2 \mathrm{a}$, randomized, double-blind 28-day study of TZP-102 a ghrelin receptor agonist for diabetic gastroparesis. Neurogastroenterol Motil. 2013;25(2): 140-e150.

23. McCallum RW, et al. TZP-102-CL-G003 phase $2 \mathrm{~b}$ study results: oral TZP-102 once daily for 12 weeks in patients with diabetic gastroparesis. Gastroenterology. 2013;144(5 suppl 1):S160-S161.

24. Shin A, et al. Randomized controlled phase Ib study of ghrelin agonist, RM-131, in type 2 diabetic women with delayed gastric emptying: pharmacokinetics and pharmacodynamics. Diabetes Care. 2013;36(1):41-48

25. Shin A, et al. The ghrelin agonist RM-131 accelerates gastric emptying of solids reduces symptoms in patients with type 1 diabetes mellitus. Clin Gastroenterol Hepatol. 2013; pii: S1542-3565(13)00578-8.

26. Leming S, et al. GSK962040: a small molecule motilin receptor agonist which increases gastrointestinal motility in conscious dogs. Neurogastroenterol Motil. 2011;23(10):958-e410.

27. Broad J, Mukherjee S, Samadi M, Martin JE, Dukes GE, Sanger GJ. Regional- and agonist-dependent facilitation of human neurogastrointestinal functions by motilin receptor agonists. Br J Pharmacol. 2012;167(4):763-774.

28. Dukes GE, et al. Safety/tolerability, pharmacokinetics (PK), and effect on gastric emptying (GE) with 14-days repeat oral dosing of the motilin receptor agonist, GSK962040, in healthy male and female volunteers. Neurogastroenterol Motil. 2010;22:14-15.

29. Wedlake L, A'Hern R, Russell D, Thomas K, Walters JR, Andreyev HJ. Systematic review: the prevalence of idiopathic bile acid malabsorption as diagnosed by SeHCAT scanning in patients with diarrhoea-predominant irritable bowel syndrome. Aliment Pharmacol Ther. 2009;30(7):707-717.

30. Sciarretta G, et al. 75Se HCAT test in the detection of bile acid malabsorption in functional diarrhoea and its correlation with small bowel transit. Gut. 1987;28(8):970-975.

31. Brydon WG, Nyhlin H, Eastwood MA, Merrick MV. Serum 7 alpha-hydroxy-4-cholesten-3-one and selenohomocholyltaurine (SeHCAT) whole body retention in the assessment of bile acid induced diarrhoea. Eur J Gastroenterol Hepatol. 1996;8(2):117-123.

32. Wong BS, et al. Increased bile acid biosynthesis is associated with irritable bowel syndrome with diarrhea. Clin Gastroenterol Hepatol. 2012;10(9):1009-1015.e3.

33. Shin A, et al. Bowel functions, fecal unconjugated primary and secondary bile acids, and colonic 
transit in patients with irritable bowel syndrome. Clin Gastroenterol Hepatol. 2013; pii: S15423565(13)00579-X.

34. Pimentel M, et al. Rifaximin therapy for patients with irritable bowel syndrome without constipation. NEngl J Med. 2011;364(1):22-32.

35. Menees SB, Maneerattannaporn M, Kim HM, Chey WD. The efficacy and safety of rifaximin for the irritable bowel syndrome: a systematic review and meta-analysis. Am J Gastroenterol. 2012;107(1):28-35.

36. Hoffman JM, et al. Activation of colonic mucosal 5-HT(4) receptors accelerates propulsive motility and inhibits visceral hypersensitivity. Gastroenterology. 2012;142(4):844-854.

37. Freiman J, et al. LX1031: inhibition of 5-HT synthesis as a new target in the management of irritable bowel syndrome (IBS). Neurogastroenterol Motil. 2009;21(9):250

38. Brown PM, et al. The tryptophan hydroxylase inhibitor LX1031 shows clinical benefit in patients with nonconstipating irritable bowel syndrome. Gastroenterology. 2011;141(2):507-516.

39. Hirata T, Funatsu T, Keto Y, Nakata M, Sasamata M. Pharmacological profile of ramosetron, a novel therapeutic agent for IBS. Inflammopharmacology. 2007;15(1):5-9.

40. Hirata T, et al. Effects of serotonin 5-HT3 receptor antagonists on stress-induced colonic hyperalgesia and diarrhoea in rats: a comparative study with opioid receptor agonists, a muscarinic receptor antagonist and a synthetic polymer. Neurogastroenterol Motil. 2008;20(5):557-565

41. Matsueda K, Harasawa S, Hongo M, Hiwatashi $\mathrm{N}$, Sasaki D. A phase II trial of the novel serotonin type 3 receptor antagonist ramosetron in Japanese male and female patients with diarrheapredominant irritable bowel syndrome. Digestion. 2008;77(3-4):225-235.

42. Matsueda K, Harasawa S, Hongo M, Hiwatashi N, Sasaki D. A randomized, double-blind, placebocontrolled clinical trial of the effectiveness of the novel serotonin type 3 receptor antagonist ramosetron in both male and female Japanese patients with diarrhea-predominant irritable bowel syndrome. Scand J Gastroenterol. 2008;43(10):1202-1211.

43. Lee KJ, et al. Efficacy of ramosetron in the treatment of male patients with irritable bowel syndrome with diarrhea: a multicenter, randomized clinical trial, compared with mebeverine. Neurogastroenterol Motil. 2011;23(12):1098-1104.

44. Bharucha AE, Ravi K, Zinsmeister AR. Comparison of selective M3 and nonselective muscarinic receptor antagonists on gastrointestinal transit and bowel habits in humans. Am J Physiol Gastrointest Liver Physiol. 2010;299(1):G215-G219.

45. Czimmer J, Süto G, Király A, Mózsik G. Otilonium bromide enhances sensory thresholds of volume and pressure in patients with irritable bowel syndrome. J Physiol Paris. 2001;95(1-6):153-156

46. Krueger D, et al. Effect of hyoscine butylbromide (Buscopan) on cholinergic pathways in the human intestine. Neurogastroenterol Motil. 2013 25(8):e530-e539.

47. Clavé P, et al. Randomised clinical trial: otilonium bromide improves frequency of abdominal pain, severity of distention and time to relapse in patients with irritable bowel syndrome. Aliment Pharmacol Ther. 2011;34(4):432-442.

48. Chang FY, Lu CL, Luo JC, Chen TS, Chen MJ, Chang HJ. The evaluation of otilonium bromide treatment in asian patients with irritable bowel syndrome. J Neurogastroenterol Motil. 2011;17(4):402-410.

49. Fukushima Y, Suzuki H, Matsuzaki J, Kiyosue A, Hibi T. Efficacy of solifenacin on irritable bowel syndrome with diarrhea: open-label prospective pilot trial. J Neurogastroenterol Motil. 2012;18(3):317-323.

50. Anderson K, Fischer L. Prevention of GI absorption of bacterial toxins: an in vitro evaluation of the potential for prophylactic use of a novel oral adsorbent (AST-120). Gastroenterology. 2008; 134(4 suppl 1):A-675

51. Tack JF, Miner PB Jr, Fischer L, Harris MS. Randomised clinical trial: the safety and efficacy of AST-120 in non-constipating irritable bowel syndrome - a double-blind, placebo-controlled study. Aliment Pharmacol Ther. 2011;34(8):868-877.

52. Lobo B, et al. Clinical benefit in IBS after disodium cromoglycate involves mast cell-mediated recovery of healthy-like innate immunity genes expression profile in the jejunal mucosa. Gastroenterology. 2009;136(suppl 1):156

53. Lobo B, et al. Clinical improvement in IBS after disodium cromoglycate involves mast cell-mediated toll-like receptor signaling downregulation. Gastroenterology. 2011;140(suppl 1):499-500.

54. Leri O, et al. Management of diarrhoeic type of irritable bowel syndrome with exclusion diet and disodium cromoglycate. Inflammopharmacology. 1997;5(2):153-158

55 . Klooker TK, et al. The mast cell stabiliser ketotifen decreases visceral hypersensitivity and improves intestinal symptoms in patients with irritable bowel syndrome. Gut. 2010;59(9):1213-1221.

56. Corinaldesi R, et al. Effect of mesalazine on mucosal immune biomarkers in irritable bowel syndrome: a randomized controlled proof-of-concept study. Aliment Pharmacol Ther. 2009;30(3):245-252

57. Andrews CN, Griffiths TA, Kaufman J, Vergnolle N, Surette MG, Rioux KP. Mesalazine (5-aminosalicylic acid) alters faecal bacterial profiles, but not mucosal proteolytic activity in diarrhoea-predominant irritable bowel syndrome. Aliment Pharmaco Ther. 2011;34(3):374-383.

58. Dorofeyev AE, Kiriyan EA, Vasilenko IV, Rassokhina OA, Elin AF. Clinical, endoscopical and morphological efficacy of mesalazine in patients with irritable bowel syndrome. Clin Exp Gastroenterol. 2011;4:141-153.

59. Tuteja AK, Fang JC, Al-Suqi M, Stoddard GJ, Hale DC. Double-blind placebo-controlled study of mesalamine in post-infective irritable bowel syndrome - a pilot study. Scand J Gastroenterol. 2012;47(10):1159-1164.

60 . Leventer SM, et al. The potential of dextofisopam for treatment of irritable bowel syndrome and inflammatory bowel disease. Am J Gastroenterol. 2004;99(suppl 5):S279.

61. Leventer SM, et al. Clinical trial: dextofisopam in the treatment of patients with diarrhoea-predominant or alternating irritable bowel syndrome. Aliment Pharmacol Ther. 2008;27(2):197-206.

62. Delvaux M, Beck A, Jacob J, Bouzamondo H, Weber FT, Frexinos J. Effect of asimadoline, a kappa opioid agonist, on pain induced by colonic distension in patients with irritable bowel syndrome. Aliment Pharmacol Ther. 2004;20(2):237-246.

63. Delgado-Aros S, et al. Effects of a kappa-opioid agonist, asimadoline, on satiation and GI motor and sensory functions in humans. Am J Physiol. 2003; 284(4):G558-G566

64. Mangel AW, et al. Clinical trial: asimadoline in the treatment of patients with irritable bowel syndrome. Aliment Pharmacol Ther. 2008;28(2):239-249.

65. Camilleri M, Lasch K, Zhou W. Irritable bowel syndrome: methods, mechanisms, and pathophysiology. The confluence of increased permeability, inflammation, and pain in irritable bowel syndrome. Am J Physiol Gastrointest Liver Physiol. 2012;303(7):G775-G785.

66. Basra S, Verne GN, Zhou Q. Randomized placebocontrolled trial of glutamine for the treatment of diarrhea-predominant irritable bowel syndrome. Gastroenterology. 2013;144(5 suppl 1):S160

67. Nullens $S$, et al. Regional colon transit in patients with dyssynergic defecation or slow transit in patients with constipation. Gut. 2012;61(8):1132-1139.
68. Cinca R, Chera D, Gruss HJ, Halphen M. Randomised clinical trial: macrogol/PEG 3350+electrolytes versus prucalopride in the treatment of chronic constipation - a comparison in a controlled environment. Aliment Pharmacol Ther. 2013;37(9):876-886.

69. Duboc $\mathrm{H}$, et al. Increase in fecal primary bile acids and dysbiosis in patients with diarrhea-predominant irritable bowel syndrome. Neurogastroenterol Motil. 2012;24(6):513-520.

70. Demaeyer JH, Lefebvre RA, Schuurkes JAJ. 5-HT4 receptor agonists: similar but not the same. Neurogastroenterol Motil. 2008;20(2):99-112.

71. Camilleri M. Pharmacology of the new treatments for lower gastrointestinal motility disorders and irritable bowel syndrome. Clin Pharmacol Ther. 2012;91(1):44-59.

72. Camilleri M, Kerstens R, Rykx A, Vandeplassche L. A placebo-controlled trial of prucalopride for severe chronic constipation. $N$ Engl J Med. 2008; 358(22):2344-2354.

73. Goldberg $\mathrm{M}$, et al. Clinical trial: the efficacy and tolerability of velusetrag, a selective 5-HT4 agonist with high intrinsic activity, in chronic idiopathic constipation - a 4-week, randomized, double-blind, placebo-controlled, dose-response study. Aliment Pharmacol Ther. 2010;32(9):1102-1112.

74. Donowitz M, et al. NHERF family and NHE3 regulation. J Physiol. 2005;567(pt 1):3-11.

75. Shailubhai K, Talluto C, Comiskey S, Foss JA, Joslyn A, Jacob G. Phase II clinical evaluation of SP-304, a guanylate cyclase-C agonist, for treatment of chronic constipation. Am J Gastroenterol. 2010;105(10):S487-S488.

76. Miner $\mathrm{P}$, et al. Plecanatide, a novel guanylate cyclase-C (GC-C) receptor agonist, is efficacious and safe in patients with chronic idiopathic constipation (CIC): results from a 951 patient, 12-week, multi-center trial. Gastroenterology. 2013;144(5 suppl 1):S163.

77. Wong B, Camilleri M, McKinzie S, Burton D, Graffner H, Zinsmeister AR. Effects of A3309, an ileal bile acid transporter inhibitor, on colonic transit and symptoms in females with functional constipation. Am J Gastroenterol. 2011;106(12):2154-2164.

78. Chey WD, Camilleri M, Chang L, Rikner L, Graffner $\mathrm{H}$. A randomized placebo-controlled phase IIb trial of a3309, a bile acid transporter inhibitor, for chronic idiopathic constipation. Am J Gastroenterol. 2011;106(10):1803-1812

79. Buchwald H, Rudser KD, Williams SE, Michalek VN, Vagasky J, Connett JE. Overall mortality, incremental life expectancy, and cause of death at 25 years in the program on the surgical control of the hyperlipidemias. Ann Surg. 2010;251(6):1034-1040.

80. Rang HP, Dale MM, Ritter JM. Analgesic drugs. Pharmacology. 1999;13(2):579-603.

81. De Schepper HU, et al. Opioids and the gut: pharmacology and current clinical experience. Neurogastroenterol Motil. 2004;16(4):383-394.

82. Pappagallo M. Incidence, prevalence, and management of opioid bowel dysfunction. Am J Surg. 2001;182(5A suppl):11S-18S

83. Candiotti KA, Gitlin MC. Review of the effect of opioid-related side effects on the undertreatment of moderate to severe chronic non-cancer pain: tapentadol, a step toward a solution? Curr Med Res Opin. 2010;26(7):1677-1684

84. Afilalo M, et al. Efficacy and safety of tapentadol extended release compared with oxycodone controlled release for the management of moderate to severe chronic pain related to osteoarthritis of the knee: results of a randomized, double-blind, placebo- and active-controlled phase 3 study. Clin Drug Investig. 2010;30(8):489-505.

85. Buynak R, et al. Efficacy and safety of tapentadol extended release for the management of chronic low back pain: results of a prospective, randomized, double-blind, placebo- and active-controlled phase III study. Expert Opin Pharmacother. 2010; 
11(11):1787-1804

86. Sykes NP. An investigation of the ability of oral naloxone to correct opioid-related constipation in patients with advanced cancer. Palliat Med. 1996 10(2):135-144

87. Vondrackova D, et al. Analgesic efficacy and safety of oxycodone in combination with naloxone as prolonged release tablets in patients with moderate to severe chronic pain. J Pain. 2008;9(12):1144-1154.

88. Meissner W, et al. A randomised controlled trial with prolonged-release oral oxycodone and naloxone to prevent and reverse opioid-induced constipation. Eur J Pain. 2009;13(1):56-64

89. Sandner-Kiesling A, et al. Long-term efficacy and safety of combined prolonged-release oxycodone and naloxone in the management of non-cancer chronic pain. Int J Clin Pract. 2010;64(6):763-774.

90. Camilleri M. Invited Review: Opioid-induced constipation: challenges and therapeutic opportunities. Am J Gastroenterol. 2011;106(5):835-842.

91. Paulson DM, et al. Alvimopan: an oral, peripherally acting, mu-opioid receptor antagonist for the treatment of opioid-induced bowel dysfunction a 21-day treatment-randomized clinical trial. J Pain. 2005;6(3):184-192.

92. Webster L, et al. Alvimopan, a peripherally acting mu-opioid receptor (PAM-OR) antagonist for the treatment of opioid-induced bowel dysfunction: results from a randomized, double-blind, placebocontrolled, dose-finding study in subjects taking opioids for chronic non-cancer pain. Pain. 2008 137(2):428-440.

93. Jansen JP, et al. A randomized, placebo-controlled phase 3 trial (Study SB-767905/012) of alvimopan for opioid-induced bowel dysfunction in patients with non-cancer pain. J Pain. 2011;12(2):185-193.

94. Irving G, et al. Study SB-767905/013) of alvimopan for opioid-induced bowel dysfunction in patients with non-cancer pain. J Pain. 2011;12(2):175-184.

95. Neumann TA, et al. Clinical investigation of oral NKTR-118 as a selective oral peripheral opioid antagonist. Proceedings of the 18th Annual Clinical Meeting of the American Academy of Pain Management. Las Vegas, Nevada, USA. September 27-30, 2007, abstract 27

96. Chey WD, et al. Efficacy and safety of naloxegol in patients with opioid-induced constipation: results from 2 prospective, randomized, controlled trials. Gastroenterology. 2013;144(5 suppl 1):S159-S160.

97. Armstrong SR, et al. The in vivo pharmacodynamics of the novel opioid receptor antagonist TD-1211, in models of opioid-induced gastrointestinal and CNS activity. Naunyn Schmiedebergs Arch Pharmacol. 2013;386(6):471-478.

98. Vickery R, Li Y-P, Kohler R, Webster L, Singla N,
Daniels O. TD-1211 demonstrates constipation-relieving effects, including decrease in rescue laxative use, in patients with opioid-induced constipation. Am J Gastroenterol. 2011;106(10 suppl 2):S513-S514.

99. Vickery RG, Li Y-P, Schwertschlag U, Singla NK, Webster L, Canafax DM. TD-1211 phase 2 b study demonstrates increased bowel movement frequency and constipation-related symptom improvement in patients with opioid induced constipation. Gastroenterology. 2013;144(5 suppl 1):S159.

100. McNicol E, Boyce DB, Schumann R, Carr D. Efficacy and safety of mu-opioid antagonists in the treatment of opioid-induced bowel dysfunction: systematic review and meta-analysis of randomized controlled trials. Pain Med. 2008;9(6):634-659.

101. Becker G, Galandi D, Blum HE. Peripherally acting opioid antagonists in the treatment of opiate-related constipation: a systematic review. J Pain Symptom Manage. 2007;34(5):547-565

102. Sloots CE, Rykx A, Cools M, Kerstens R, De Pauw $M$. Efficacy and safety of prucalopride in patients with chronic noncancer pain suffering from opioid-induced constipation. Dig Dis Sci. 2010 55(10):2912-2921

103. Cryer BL, et al. A phase 3, randomized, doubleblind, placebo-controlled clinical trial of lubiprostone for the treatment of opioid-induced bowel dysfunction in patients with chronic, non-cancer pain. Gastroenterology. 2010;138(suppl 1):S129.

104.Jamal MM, Mareya SM, Woldegeorgis F, Joswick TR, Ueno R. Lubiprostone significantly improves treatment response in non-methadone opioid-induced bowel dysfunction patients with chronic, non-cancer pain: results from a phase 3 , randomized, double-blind, placebo-controlled clinical trial. Gastroenterology. 2012;142(suppl 1):S144-S145.

105. Cuppoletti J, Chakrabarti J, Tewari K, Malinowska DH. Methadone but not morphine inhibits lubiprostone-stimulated Cl- currents in T84 intestinal cells and recombinant human ClC-2, but not CFTR Cl- currents. Cell Biochem Biophys. 2013;66(5):53-63.

106. Ruepert L, Quartero AO, de Wit NJ, van der Heijden GJ, Rubin G, Muris JW. Bulking agents, antispasmodics antidepressants for the treatment of irritable bowel syndrome. Cochrane Database Syst Rev. 2011;(8):CD003460.

107. Parkman HP, et al. Nortriptyline for idiopathic gastroparesis: a multicenter, randomized, doublemasked, placebo-controlled trial (NORIG). Gastroenterology. 2013;144(5 suppl 1):S1.

108. Corsetti M, Tack J. FDA and EMA end points: which outcome end points should we use in clinical trials in patients with irritable bowel syndrome? Neurogastroenterol Motil. 2013;25(6):453-457.

109. Talley NJ, Choung RS, Camilleri M, Dierkhising
RA, Zinsmeister AR. Asimadoline, a K-opioid agonist, and satiation in functional dyspepsia. Aliment Pharmacol Ther. 2008;27(11):1122-1131.

110. Hellström PM, Hein J, Bytzer P, Björnssön E, Kristensen J, Schambye H. Clinical trial: the glucagon-like peptide- 1 analogue ROSE-010 for management of acute pain in patients with irritable bowel syndrome: a randomized, placebo-controlled, double-blind study. Aliment Pharmacol Ther. 2009;29(2):198-206.

111. Camilleri M, et al. Effect of a glucagon-like peptide 1 analog, ROSE-010, on gastrointestinal motor functions in females with constipation-predominant irritable bowel syndrome. Am J Physiol Gastrointest Liver Physiol. 2012;303(1):G120-G128.

112.van Wanrooij S, Wouters MM, Van Oudenhove L, Vermeire S, Rutgeerts PJ, Boeckxstaens GE. Effect of the H1-receptor antagonist ebastin on visceral perception and clinical symptoms in IBS. Gastroenterology. 2013;144(5 suppl 1):S160.

113. Tack JF, et al. Efficacy of ibodutant, a selective antagonist of neurokinin 2 receptors, in irritable bowel syndrome with diarrhea (IBS-D): the results of a double-blind, randomized, placebo-controlled, parallel-group phase II study. Gastroenterology. 2013; 144(5 suppl 1):S92-S93.

114. Bredenoord AJ, Chial HJ, Camilleri M, Mullan BP, Murray JA. Gastric accommodation and emptying in evaluation of patients with upper gastrointestinal symptoms. Clin Gastroenterol Hepatol. 2003;1(4):264-272

115. Tack J, Janssen P, Masaoka T, Farré R, Van Oudenhove L. Efficacy of buspirone, a fundus-relaxing drug, in patients with functional dyspepsia. Clin Gastroenterol Hepatol. 2012;10(11):1239-1245.

116. Miwa H, et al. Efficacy of the 5-HT1A agonist tandospirone citrate in improving symptoms of patients with functional dyspepsia: a randomized controlled trial. Am J Gastroenterol. 2009;104(11):2779-2787.

117. Tack J, et al. A dose-ranging, placebo-controlled pilot trial of acotiamide in patients with functional dyspepsia. Neurogastroenterol Motil. 2009;21(3):272-280.

118. Matsueda K, Hongo M, Tack J, Saito Y, Kato H. A placebo-controlled trial of acotiamide for mealrelated symptoms of functional dyspepsia. Gut. 2012;61(6):821-828.

119. Kusunoki $\mathrm{H}$, et al. Therapeutic efficacy of acotiamide in patients with functional dyspepsia based on enhanced postprandial gastric accommodation and emptying: randomized controlled study evaluation by real-time ultrasonography. Neurogastroenterol Motil. 2012;24(6):540-545.

120.Camilleri M. Current and future pharmacological treatments for diarrhea-predominant irritable bowel syndrome. Expert Opin Pharmacother. 2013; 14(9):1151-1160 